\section{Antropología de la conservación y el manejo de recursos naturales: tensiones y desafíos para la práctica antropológica*}

Anthropology of natural resources preservation and management: tensions and challenges for the anthropological practice

\section{Editado por Francisco Araos ${ }^{*} \mathrm{Y}$ Daniela Serra ${ }^{* * *}$}

Esta sección especial de la Revista Austral de Ciencias Sociales que se presenta a continuación surge como resultado del simposio "Antropología de la conservación y el manejo de recursos naturales: tensiones y desafíos para la

\footnotetext{
En la edición de esta sección los editores contaron con el apoyo de los proyectos CONICYT/FONDECYT/PROYECTO N ${ }^{0} 3150341$ y CONICYT/PAI/CONCURSO NACIONAL INSERCIÓN DE CAPITAL HUMANO AVANZADO EN LA ACADEMIA CONVOCATORIA AÑO 2017/ PROYECTO № 79170113.

** Universidad de Los Lagos, Centro de Estudios del Desarrollo Regional y de Políticas Públicas. francisco.araos@ulagos.cl

*** Doctora en Antropología y Medio Ambiente Universidad de Otago, Nueva Zelandia. daniela.matakuri2@gmail.com
}

práctica antropológica" realizado durante el IX Congreso Chileno de Antropología, en la ciudad de Castro, Chiloé, en enero del año 2017. Este encuentro tuvo como objetivo fomentar el debate y la colaboración para el estudio de las dimensiones humanas de la conservación de la biodiversidad y el manejo de recursos naturales en Chile, explorando las transformaciones que estos dos fenómenos han generado en las relaciones entre cultura, naturaleza y sociedad. El simposio se enfocó en el análisis de las tensiones y desafíos que implica el encuentro entre desarrollo económico, conservación y bienestar humano, presentando diversas investigaciones que describen acciones colectivas de resistencia, de demandas de derechos colectivos sobre los recursos naturales y estrategias de apropiación social de la conservación y el discurso ambiental.

Esta sección especial reúne ocho artículos, seis de ellos presentados inicialmente en el simposio y dos que se sumaron en convocatorias posteriores. Cabe destacar que los trabajos congregan diversos enfoques teóricos y disciplinas interesadas en el tema como la antropología, la sociología y la geografía, que confluyen, en su mayoría, en el análisis de las dimensiones humanas de la conservación desde la ecología política y los estudios socioambientales. Asimismo, los trabajos reflejan un amplio espectro generacional de investigadores, reuniendo autores consolidados en las ciencias sociales del país con emergentes investigadores que presentan sus primeros trabajos y reflexiones.

En términos espaciales los artículos cubren una gran parte del territorio nacional, incluyendo ecosistemas terrestres, costeros e insulares, 
así como paisajes de montaña, de valle y litoral. Una parte importante de los trabajos se concentran en la zona sur austral de Chile, un territorio donde-como muestran los artículos- la conservación de la biodiversidad se ha tornado un factor decisivo para el desarrollo regional, un lugar particularmente rico para el estudio de las interrelaciones entre naturaleza y sociedad.

El dossier abre con el artículo de Macarena Libuy, texto que nace del trabajo etnográfico de la investigadora en los poblados de Puyuhuapi y Cerro Castillo, en la Región de Aysén, en la Patagonia chilena. Desde una perspectiva que concibe la conservación de la biodiversidad como una manifestación del proceso de mercantilización de la naturaleza, la autora discute los impactos que las áreas protegidas -públicas y privadas- han provocado en las relaciones simbólicas y materiales de los habitantes de estos dos poblados con el bosque -el monte para los actores locales-, evidenciando las tensiones y disputas generadas por el contencioso encuentro entre diferentes formas de apropiación de la naturaleza. Un retrato etnográfico de las fricciones de los ensamblajes conservacionistas en la Patagonia chilena que permite visualizar las múltiples formas de operar de las políticas de la naturaleza desplegadas en esta región del país.

Siguiendo en la Patagonia, el artículo de Andrés Núñez, Enrique Aliste, Álvaro Bello y Pablo Astaburuaga, coloca en perspectiva el fenómeno de mercantilización de la naturaleza descrito en el trabajo anterior, enmarcándolo en un amplio proceso de transformación del uso y apropiación de la tierra; desde un extractivismo ganadero y forestal de los colonos patagones, a un "eco-extractivismo" conservacionista dominado por corporaciones privadas, que configura un nuevo escenario territorial.
"Aysén, Reserva de Vida"1 emerge como el símbolo de este nuevo desarrollo, un "mito que cubre de pureza" los arreglos de poder "ecoextractivistas" que definen el devenir de este territorio en la actualidad.

El tercer artículo viene a cerrar el capítulo dedicado a la Patagonia. En éste, Juan Carlos Rodríguez, Fernando Mandujano y Rodrigo Vargas, analizan las implicancias del proceso de re-construcción territorial impulsado por la conservación y la sustentabilidad. En este sentido, los autores destacan las tensiones que se generan entre el modo de vida eminentemente rural de las poblaciones tradicionales de colonos patagones y la nueva ruralidad impulsada por el turismo y el desarrollo inmobiliario en clave ecosustentable.

En suma, estos tres trabajos muestran que bajo la aparente calma y equilibrio del wilderness ${ }^{2}$ patagónico se traban incesantes relaciones de poder que están redefiniendo el modo de apropiación de la naturaleza y sus recursos, orientando la conservación de la biodiversidad hacia un eco-capitalismo dominado por agentes estatales y privados. Por el momento, los autores concuerdan en la posición hegemónica de esta visión de la conservación y la sustentabilidad ambiental, una tendencia que tiende a ser matizada y friccionada en los siguientes trabajos al mostrar algunas alternativas que vienen a contrarrestar y re-articular la conservación de la biodiversidad con la incorporación de preocupaciones asociadas a la interculturalidad, las relaciones inter-especies y la ciudadanía.

Slogan utilizado por el Gobierno Regional de Aysén para simbolizar la estrategia de desarrollo regional.

El concepto de wilderness hace referencia a zonas de naturaleza salvaje, prístina e intocada por el hombre. 
El primero de ellos es el artículo de los gestores y funcionarios de la Corporación Nacional Forestal (CONAF), quienes presentan y analizan la implementación de la gestión intercultural en áreas silvestres protegidas del Estado. A partir de casos emblemáticos a nivel nacional, como la Reserva Nacional Los Flamencos en el desierto de Atacama y el Parque Nacional Rapa Nui, los autores destacan la relevancia de establecer acuerdos y relaciones horizontales de gobernanza de la áreas protegidas, integrando a las comunidades en los procesos de toma de decisiones. No obstante, advierten sobre la necesidad de ir más allá de los acuerdos locales y asumir la gestión intercultural como una política de Estado, incorporando la participación social como un paradigma central en el ejercicio de la gestión de la biodiversidad.

En seguida, se presenta el artículo de Daniela Serra sobre el proceso de creación y gestión del Área Marina Protegida Lafken Mapu Lahual, en la costa de la región de Los Lagos. En este trabajo la autora analiza la incorporación del mundo indígena en la gestión de la biodiversidad marinocostera en Chile. El artículo revela la manera en que la visión utilitarista de los agentes políticos y técnicos sectoriales, sometió la complejidad sociocultural de los grupos y colectivos locales al carácter de usuarios de los recursos naturales, lo que impactó en la gobernanza y apropiación de la iniciativa de conservación marina.

Finalmente, el trabajo de Martin Fonck y Daniela Jacob presenta los resultados de una investigación etnográfica realizada en la zona cordillerana de la Región de La Araucanía. Enmarcándose en el intenso debate actual sobre las relaciones entre humanos y no humanos, los autores analizan las relaciones de afecto y las continuidades inter-especies -entre campesinos, ambientalistas, guías turísticos, vacas, aves y árboles- que se entraman en el Santuario el Cañi. Un ensamblaje conservacionista que lleva a preguntarse por las implicancias políticas de este giro ontológico; desde una conservación socialmente inclusiva a una conservación orientada a la relaciones inter-especies, una transición que remite a la constitución de un nuevo pacto que implica el reconocimiento de los derechos de todos los seres vivos que habitan el planeta.

Cerramos esta sección con dos artículos que nos traen a la zona central y centro sur del país, enfocando el análisis en la participación social y la ciudadanía en contextos de conservación y sustentabilidad. Primero el trabajo de Paolo Perasso, Constanza Christian y Daniela Carvajal, discute los mecanismos de participación social en tres iniciativas socioambientales desarrolladas por ONGs, gobierno y universidades. A partir del análisis de los casos, los autores discuten acerca del papel de los antropólogos en la mediación socioambiental, los beneficios de la etnografía para acercar las posiciones divergentes y la relevancia de generar el adecuado balance entre consulta ciudadana, participación social y legitimidad de las decisiones.

El último artículo presenta el trabajo Héctor Santibañez sobre conflictos socioambientales en la región metropolitana de Valparaíso. A partir de la revisión de tres casos emblemáticos, como la explotación inmobiliaria de las dunas de Concón, el autor analiza las acciones colectivas de protesta y reivindicación ciudadana surgidas en estos eventos y la emergencia de la conservación como una herramienta política de justicia socioambiental. Más allá de los casos particulares, el trabajo de Santibañez permite 
comprender el papel que pueden ejercer las áreas protegidas en el contexto metropolitano y los desafíos que coloca para la gestión urbana. En suma, los diferentes artículos que se presentan muestran la pertinencia del debate antropológico sobre las dimensiones humanas de la conservación y el manejo de recursos naturales, las interfaces con otras disciplinas y enfoques, y la diversidad de problemas y preguntas que componen este nuevo campo de investigación. Los casos y experiencias aquí expuestas representan una interesante muestra para vislumbrar la complejidad de este fenómeno socioambiental y un punto de partida para proyectar futuras colaboraciones.

Agradecemos a todos los académicos e investigadores que colaboraron en el arbitraje de los artículos y a los editores de la Revista Austral de Ciencias Sociales. 